\title{
POPULAÇÃO E PROCESSO DE ESTRUTURAÇÃO DO ESPAÇO GEOGRÁFICO ${ }^{*}$ )
}

\author{
Ana Fani Alessandri Carlos (*\%) \\ Rosa Ester Rossini ( $\$$ )
}

\section{INTRODUÇÃO}

A noção de espaço vem sendo objeto de preocupação de vários campos do conhecimento.

A Geografia, que tem o espaço como objeto primeiro de seus estudos, tem elaborado trabalhos em diferentes linhas teóricas. A discussão do conceito nos trabalhos geográficos, não cabe aqui, pois, além de ser longa, não é conclusiva. Adotaremos a noção de espaço-produto.

O espaço será visto, portanto, como fruto das relações que se estabelecem entre a sociedade e o meio circundante, num determinado momento do desenvolvimento das forças produtivas. Ele é produzido concomitantemente ao processo de produção da existência humana. A sociedade, ao mesmo tempo que produz sua existência, produz o espaço: "A história não se escreve fora do espaço e não há sociedade a-espacial. O espaço, ele mesmo é social”. (SANTOS, 1979, p. 10).

Consideramos, assim, o espaço geográfico como produto histórico que sofreu e sofre um processo de acumulação técnico-cultural, e que, por conseqüência, apresenta em cada momento as características da sociedade que o produz. Ele não deve ser visto, de modo algum, como o cerceamento da ação humana, o palco onde os homens habitam, pois a idéia de espaço-produto não pode estar relacionada à de receptáculo, elemento passivo e inerte.
O espaço como produto social é processo de produção concreto, nascido do trabalho, que por seu lado nada mais é do que a resposta do homem a uma série de necessidade a que ele deve satisfazer para sobreviver. Portanto, a gênese do espaço geográfico é a existência humana, condição essencial para que o homem possa "fazer história", produzir e transformar seu próprio espaço. É a ação humana consciente que transforma o meio natural em espaço. (Carlos, 1979 (p. 27/37).

Qualquer elemento da realidade circundante deve ser analizado pelo geógrafo a partir dessa preocupação. É este enfoque que vai individualizar seu trabalho, diferenciando-o do economista, do sociólogo ou do historiador.

Apesar disso, tem-se claro que a realidade é una, é uma totalidade concreta, dialeticamente articulada e é essa unidade do real que será a premissa básica da unidade da ciência. Isso quer dizer que se por um lado o enfoque de cada pesquisador é específico, o pano de fundo da explicação do fenômeno é um só.

(*) - O presente artigo foi originariamente publicado sob o título de: "The struturation of space regional patterns: population, in IGU Latin American conference Brasilian geographical studies vol. I, Rio de Janeiro, 1982. Entregue para publicação em 14 de junho de 1982, na Revista do Departamento de Geografia.

(**) - Respectivamente: Professora Assistente e Professora Assistente Doutora do Departamento de Geografia. FFLCH - USP. 
A colocação dessas idéias preliminares é fundamental na medida em que coloca os pressupostos a partir dos quais desenvolveremos nossa breve análise do tema proposto.

Inicialmente, deve-se reafirmar que não se pode tratar da estruturação do espaço sem incluir o papel da população nesse processo. Apesar de encontrarmos especificidade a nível macro-regional, regional e local, a estruturação de quaisquer desses espaços obedece a pressupostos teóricos gerais da produção e estruturação do espaço geográfico global. As relaçōes tendem a se reproduzir de modo semelhante em diferentes escalas, uma vez que o espaço global forma uma totalidade concreta, onde os elementos vão se estruturando dialeticamente, em função de leis gerais.

A noção de espaço-palco, defendida até recentemente, nos remetia à noção de arranjo, de ordenação, "empreendimentos destinados a modelar o espaço herdado para neles se introduzirem as estruturas técnicas, jurídicas e administrativas, que derivam de um espírito rico de sistematização da sua utilização". (George, s.d., p. 5/7).

Conseqüentemente, o estudo da população se resumia, nessa concepção, a um fenômeno meramente quantitativo e muito pouco qualitativo. Os temas eram desenvolvidos através de capítulos, tais como a distribuição da população sobre o globo, sua repartição em sexo ou setores de atividades, etc. A população tornava-se uma abstração quantitativa - mera enumeração cronológica dos dados - cuja distribuição espacial assumia mais uma dose de fatalismo do que uma análise concreta de situações concretas, em processo permanente de transformação.

Outros autores, partindo dessa concepção, introduzem seus estudos fazendo um histórico dos dados brutos no tempo, sem preocupação com a análise dos processos que permitem a apreensão da produção do espaço geográfico.
Esse "fatalismo" acima referido é encontrado em textos de vários autores de grande reputação científica. "A mais inelutável das razões da desigualdade entre os homens é hoje a sua origem geográfica, isto é, o lugar onde nascem". (George, 1971, p. 9).

Beaujeu-Garnier em seu famoso Geografia da População trabalha $\mathrm{o}$ assunto seguindo praticamente o mesmo pressuposto teórico. Percebe-se, em seu trabalho, até mesmo uma orientação malthusiana: "Poder-se-a perguntar até onde irá essa maré humana e quanto tempo nosso pequeno planeta poderá conter, e acima de tudo, alimentar todos esses milhões”. (Beaujeu-Garnier, 1980, p. 3).

Radicalmente diferente é a abordagem a partir do espaço-produto. Em primeiro lugar, porque o espaço é encarado como um produto social. Sendo a produção incessante e ininterrupta, o espaço não é algo pronto e acabado, está em contínuo movimento. É o resultado da matéria trabalhada em sua totalidade. É exclusivamente dinâmico, pois o movimento jamais termina, especialmente porque se considera que a produção do espaço é fruto da existência humana, isto é, do trabalho humano. A partir da relação de trabalho - através do processo de produção - a sociedade não só transforma o meio circundante em espaço produzido, como também se modifica nesse processo.

Existe um dinamismo que é inerente ao processo de produção geral, do qual a população é o agente, é o elemento produtor. A população, nesse sentido, não é uma simples abstração, mas é sinônimo de sociedade, de uma sociedade histórica, da qual os elementos participam de maneira difenciada pelo "lugar que ocupam dentro do sistema de produção historicamente determinado; pelas relações que se encontram frente aos meios de produção, pelo papel que desenvolverão na organização do trabalho e pelo modo e proporção em que recebem parte da riqueza social de que se dispõe". (Lenin, 
1974, p. 87), isto é, uma sociedade dividida em classes sociais e não simplesmente agrupamentos humanos, como faz Le Lannou, Beaujeu-Garnier, George e outros. O homem não vive agrupado, o homem é um ser social e vive e se reproduz em sociedade. O processo de universalização do homem, o tornar-se humano é para Marx (1968, vol. II e III p. 7/12) a passagem do particular ao genérico, isto é, a constituição da pessoa que se dá pela troca (não como relação de igualdade, mas como relação social) de produtos para a satisfação das necessidades humanas. A produção do humano é um processo ininterrupto, onde a transformação da sociedade, se dá a partir de relações sociais concretas e não relações ideais. O homem se faz histórico através das relações concretas que ele mesmo cria na e através da sociedade. Daí a popopulação não poder ser tratada como uma abstração.

Também as causas da distribuição ou repartição espacial, antes de se encontrarem nos fatores naturais associados aos históricos, como fazem alguns autores, devem ser buscadas na história e nas relações sociais que a produzem, onde o meio natural tem cada vez um papel de menor impartância, devido ao estágio atual alcançado pelo desenvolvimento das forças produtivas. A desigual distribuição da população refere-se à desigualdade do processo de produção que se desenvolve a partir da divisão do trabalho, que separa cidade de um lado, campo do outro. Isso determinará o papel de cada parcela do espaço na produção geral, tanto dos homens quanto do espaço geográfico.

Assim, a nosso ver, discutir o problema da "geografia da população" não é simplesmente reproduzir as idéias de Marx a respeito da população como alguns já fizeram, mas pensar a população do ponto de vista geográfico, através do materialismo histórico, o que é bem diferente.

Isso quer dizer que teremos que pensar a população como uma sociedade de classes, no seu papel enquanto produtora do espaço geográfico e, conseqüentemente, a apropriação desse produto criado no processo de produção social. O espaço geográfico é um espaço humanizado exatamente pelo fato de a sociedade produzi-lo e apropriar-se do objeto produzido, e não pelo fato de habitá-lo.

\section{I}

Feitas as colocações iniciais, podemos então partir para a questão da estruturação do espaço.

Se o próprio ato de produzir a existência humana é ao mesmo tempo o ato de produzir o espaço, como esse processo se realiza? Podemos partir inicialmente do ato de produção em sí, isto é, da existência humana.

Sem nos alongarmos demais, porque Marx e Engels já trataram desse assunto, para que haja história é necessário que haja seres humanos vivos, e a manutenção dos seres humanos depende, antes de mais nada, da satisfação de necessidades básicas, tais como: alimentação, vestuário, abrigo etc.. A satisfação dessas necessidades é o primeiro fato histórico, e essa satisfação gerará como conseqüência novas necessidades.

A satisfação dessas necessidades só pode dar-se mediante o trabalho (num primeiro momento da história da humanidade um trabalho de simples coleta, que tornava o homem um elemento passivo, um ser produzido, até chegar ao trabalho transformador, que tornava o homem um elemento produtor). A atividade do trabalho se estabelece entre o homem e a natureza e dependerá da destreza, da técnica, dos instrumentos de trabalho, isto é, do estágio de desenvolvimento das forças produtivas.

$\mathrm{Na}$ medida em que o homem transforma a natureza, criando os produtos de suas necessidades, ele está plantando e com isso mexendo a terra e dando-lhe um outro significado, através do seu cultivo: a escolha do que nela será plantado, com que 
técnicas, com que ferramentas, com que relação de trabalho. Ele está também criando sua moradia: a construção, o plano, o material utilizado dependerão também do momento histórico de produção. Traz água para perto da casa e da plantação (os diques, canais e valas de irrigação datam do IV milênio A.C.), cria algum sistema de comunicação que the permita trocar seu excedente (mesmo que a tônica da produção seja de auto subsistência). Dessa primeira troca, generaliza-se o processo de produção para o mercado e não mais para a família, e com isso se cria cada vez mais um laço de relações entre pessoas e entre lugares

A partir da relação que o homem mantém com a natureza, em função de sua subsistência, da manutenção da vida; ao mesmo tempo em que está transformando a natureza herdada em algo próprio do homem, vai-se estruturando e se produzindo um espaço.

Daqui se depreende que o que leva inicialmente o homem a se relacionar com a natureza é a luta pela sua sobrevivência. O suprimento das necessidades vitais associadas a essa luta é o objetivo final de sua relação com o espaço. Através do trabalho, o homem atua, visto que a sociadede humana, enquanto vive, é obrigada a procurar sua energia material no mundo exterior. O caráter intencional e voluntário do trabalho leva à transformação do objeto em algo apropriado ao ser humano. O espaço é "humanizado" pelo fato de o homem humanizar e tornar próprio dele o objeto sobre o qual recai o trabalho.

Como a matéria prima para o trabalho vem da natureza e como o homem vive num determinado lugar, além de retirar a matéria prima, ele transforma essa natureza, humanizando-a e incorporando-a ao seu universo, em suma apropriando-se dela.

A tese de que partimos é a de que o espaço é uma produção humana e seu processo de criação e transformação é determinado pelo modo através do qual os homens produzem sua existência, isto é, pelo modo de produção vigente. Mas como o modo de produção é apenas um elemento da totalidade determinante e por ela determinado, o processo de produção espacial deve ser analisado a partir dessa totalidade - ou seja, a categoria mais geral: formação econômica da sociedade.

Assim sendo, se o ato de produzir é concomitantemente o ato de produção do espaço, é nesse sentido que o geógrafo analisará o processo de produção: enquanto processo social e histórico, produtor do espaço geográfico. Isso não quer dizer que ele deva se abster das relações reais e concretas que determinam e criam as leis e os objetivos desse modo de produção - e isto se dá no nível da super estrutura (política, ideológica, jurídica e religiosa) da formação econômica da sociedade à qual esse modo de produção pertence.

Se o processo de produção da existência e concomitantemente o processo de produção do espaço são determinados historicamente, o espaço geográfico hoje (no caso dos países capitalistas) terá sua produção determinada pela formação econômica da sociedade capitalista, diversa da feudal e da socialista.

Nesse sentido, é necessário refletir como esses dois processos de produção se realizam do ponto de vista da população, já que ela é o agente do processo.

Em primeiro lugar, a população não se refere a uma somatória de indivíduos (como já foi colocado anteriormente) mas a uma sociedade de classes.

Em segundo lugar, trata-se de estabelecer como essa sociedade produz o espaço geográfico já que ela o faz através da relação de trabalho. Portanto, o que nos interessa inicialmente é a população trabalhadora - a força de trabalho - como ela vai produzir, com que instrumentos, como o 
trabalho será dividido e organizado. Essa é também uma população consumidora na medida em que se apropria desse espaço para suprir suas necessidades. Na medida em que ela está consumindo, está impulsionando a produção. $O$ consumo dos produtos do trabalho, no entanto, será determinado pela produção: o consumo privado, que se dá através do habitar e consumo coletivo, através do lazer, locomoção, saneamento, etc. $\mathrm{O}$ acesso a esse consumo é bastante desigual, pois enquanto o processo de produção é uma tarefa coletiva, o produto do processo de trabalho é privado. Essa apropriação privada e desigual do espaço geográfico produzido pelo trabalho da sociedade pode ser percebida através da paisagem urbana, que coloca, lado a lado, favelas, conjuntos habitacionais, mansões e luxuosas casas e apartamentos. Isso quer dizer que pelo fato de o processo de trabalho sob - modo de produção capitalista ser alienado, a sociedade participa desigualmente da distribuição dos frutos do trabalho.

A apropriação do espaço geográfico se dá formalmente através da apropriação da terra. Mas "na verdade, quando o capitalista se apropria de uma determinada parcela do espaço, ele o está fazendo apropriando-se de tudo o que ele contém" (Carlos e Lencione, 1981, p. 304): sistema de transportes, saneamento, educação, saúde, porque esta porção se insere num espaço global.

Se o processo de produção do espaço é um processo de trabalho, as parcelas do espaço global se articulam e se integram a partir do papel que cada uma terá no processo de trabalho geral. A divisão do trabalho se especializa criando espaços diferenciados não só como cidade de um lado (onde predomina o trabalho industrial e comercial) e campo do outro (onde predomina o trabalho agrícola) como também especializações espaciais dentro de cada atividade: seja industrial, comercial ou agrícola .

Estabelece-se a partir daí uma diversidade de relações com intensidades desiguais que vão produ- zir o espaço global através da produção de parcelas espaciais menores.

Como desvendar a peculiaridade dessa produção espacial sob a égide formação econômica da sociedade capitalista? Na formação econômica da sociedade capitalista, a categoria determinante da análise é o capital. Deste modo, teremos uma produção espacial voltada para as exigências e necessidades do capital; uma população que se produzirá e reproduzirá em função de suas leis e, conseqüentemente, um processo de apropriação que the será peculiar.

\section{Do ponto de vista do processo de produção.}

A produção capitalista pressupõe a expropriação da população de modo a que o trabalhador só tenha a vender sua força de trabalho. Portanto, pressupõe um mercado de trabalho. Por outro lado, as mercadorias produzidas no processo produtivo devem ser adquiridas, isto é, vendidas e consumidas para que a produção se viabilize. Para se agilizar o ciclo do capital é necessário que o capitalista não saia do processo de produção para vender sua mercadoria, e deste modo o processo de produção cria toda uma gama de atividades (circulação, distribuição e troca) que ligam o processo de produção ao de consumo.

No modo de produção capitalista, a indústria assume o papel dirigente da economia, subordinando, criando e redifinindo outras atividades, tornando a agricultura um ramo seu. A indústria é a célula básica do processo produtivo. O desenvolvimento do processo de industrialização tende a eliminar a produção artesanal atomizada e transformar o processo produtivo numa produção "seriada de máquinas e processos de tal modo a reduzir a manipulação a um mínimo a arrumar a montagem e outras operações num transportador contínuo ou intermitente com os 
processos altamente subdivididos e padronizados". (Dobb, 1978, p. 179/80).

O processo de produção capitalista, cujo objetivo é a produção da mais valia, pressupõe para sua reprodução a "continuidade" e a "produção em escala".

A produção em grande escala por um lado é condição necessária à continuidade do processo. O capitalista visa ao aumento da produtividade do trabalho, diminuindo o custo dos produtos e a parte da jornada de trabalho dedicada ao trabalio necessário.

Por outro lado, a questão da continuidade no processo produtivo é a característica da produção capitalista determinada pela base técnica, e implica em tornar todo o processo cíclico em sua unidade, sem que o processo seja interrompido.

Essas duas características tendem a aumentar a concentração espacial na medida em que obriga a integração e aprofunda a divisão do trabalho entre os ramos da economia, e deste modo reforça a dependência das parcelas do espaço, englobando-as no processo produtivo geral, através da divisão espacial do trabalho.

A concentração do capital e a decorrente concentração espacial das atividades, no modo de produção capitalista, posuem um nexo comum. Como a concentração do capital tende a ultrapassar os limites impostos pela tecnologia industrial, a concentração espacial também tende a ser muito maior que a decorrente das necessidades técnicas do processo produtivo.

E preciso notar que a tendência à super concentração urbana, entendida como concentração de atividades e de população em uma ou poucas unidades, em detrimento do resto da "rede urbana", acima dos requisitos da tecnologia, é uma contradição que o capitalismo apresenta tanto em países desenvolvidos (Inglaterra, França, Itália) quanto em países não desenvolvidos (como o Brasil).

A urbanização é um fenômeno que não pode ser estudado em si, ou simplesmente ligado ao processo de industrialização. Na realidade, o processo se dá na medida em que se estabelece o surgimento e a expansão do capital através do processo de acumulação. O tipo de urbanização atual é um fenòmeno puramente capitalista. Urbanização e acumulação são processos decorrentes da evolução cada vez mais ampliada do processo produtivo.

A formação das grandes metrópoles é decorrente da concentração do processo produtivo e, conseqüentemente' do processo de acumulação em pontos estratégicos do território e que comanda o processo de produção através da divisão do trabalho entre espaços hierarquizados do território e da expropriação do excedente gerado nesses espaços.

O processo de reprodução das relações capitalistas cria, assim, um sistema articulado e dependente, inerente à reprodução do próprio sistema de produção.

O processo de produção e acumulação capitalista no Brasil criou, com a implantação da indústria em São Paulo, toda uma reestruturação da divisão espacial do trabalho sob o controle da metrópole paulista.

\section{Do ponto de vista da população.}

Aqui podemos fazer uma separação entre: a) a parcela da população que constrói objetivamente o espaço produzido que é a força do trabalho social viva - e que engloba necessariamente o processo de acumulação passado; b) a parcela da população que não produz diretamente o espaço.

No primeiro caso é necessário reafirmar o que dissemos anteriormente - que o trabalho que produz (no processo de produção) os produtos neces- 
sários à produção da existência humana, está concomitantemente produzindo o espaço; logo é necessário refletir sobre essa produção do ponto de vista das forças produtivas e de seu desenvolvimento.

Do ponto de vista da população, o processo de desenvolvimento da produção capitalista exige inicialmente a expropriação dos meios de produção de uma parcela grande da população. Essa parcela majoritária constitui uma classe que tem como condição única de sobrevivência a venda de sua força de trabalho, isto é um contingente de "homens livres", despojados de seus meios de produção, prontos a vender sua força de trabalho ao capitalista, como forma de assegurar sua existência.

Com a acumulação e o conseqüente desenvolvimento das forças produtivas do trabalho, cresce a força da expansão do capital para além das condições técnicas que o próprio processo de produção permite, transformando rapidamente o produto excedente em novos meios de produção. No entanto, as variações absolutas da acumulação do capital se refletem sob a forma de variações relativas da massa de força de trabalho explorável, o que induz a oscilações.

Quanto à classe de proletários, o que ocorre é que o capital e a sua conseqüente reprodução ampliada reproduz constantemente dois fenômenos: a) o da população ativa, que trabalha para a produção do capital; b) uma população disponível, que não é absorvida pelo capital, e que forma o exército industrial de reserva.

E necessário para o sistema ter grandes massas de homens disponíveis para poder lançá-los em momentos decisivos sem que a escala de produção seja quebrada (é necessário agilizar e viabilizar o ciclo do capital sem interrupções).

A reprodução dos homens é necessária para servir de mercadoria para o capital.
O ciclo do capital é determinado através de sua composição orgânica, que por sua vez é determinada pelo grau de acumulação do capital.

A reprodução enquanto reprodução da vida, da espécie, é dada pela T.N. (taxa de natalidade) e o nível de reprodução será determinado pelo salário, que é decorrente do lugar que o indivíduo tem na classe e, conseqüentemente, no processo de produção com a respectiva remuneração daí decorrente.

A reprodução dos homens, de um modo geral, está ligada à forma específica do sistema capitalista de gerar valor a partir da apropriação do trabalho não retribuído.

Isso quer dizer que a reprodução dos homens no modo de produção capitalista assume uma especificidade histórica que a difere de períodos precedentes, criando uma lei de população específica; isto é, o capital, de acordo com suas necessidades, se esforçará para aumentar a população operária, ao mesmo tempo em que diminui constantemente o tempo de trabalho necessário. Aqui reside uma das grandes contradições do capitalismo, pois ao mesmo tempo em que ele cria o sobretrabalho, está abolindo o trabalho necessário, e o primeiro só pode existir a partir do segundo. Por outro lado, a noção da superpopulação se associa diretamente à privação do indivíduo das condições de reprodução de sua própria existência; desse modo, num determinado momento do desenvolvimento da produção social, pode ou não existir superpopulação.

Os limites da população dependem da elasticidade da forma de produção determinada. Elas variam, contraem-se ou dilatam-se, segundo suas condições. A taxa de crescimento absoluto da população se modifica; em conseqüencia, também a da superpopulação. É a base produtiva que determina a cada momento a superpopulação, do mesmo que determina a produção ótima. A população total é assim, a população necessária e a população excedente, que uma determinada base produtiva 
teria condições de criar. A historia mostra que a população se desenvolve em relações muito diversas e que tanto população necessária quanto população excedente são relações históricas. Desse modo, a população não pode ser determinada por números, nem por um limite absoluto de produtividade de alimentos, mas ao contrário, é determinada e tem seus limites fixados pelas condições da produção. O movimento da população total (população necessária e população excedente) é dado por leis históricas do emprego, que fazem com que o indivíduo participe da população necessária ou da excedente, que determinarão o grau de reprodução humana do trabalhador assalariado.

Mas tanto a população efetivamente "ativa" ou trabalhadora, quanto a população excedente são criadas concomitantemente e articuladas pelo modo de produção baseado no capital e em função de suas necessidades. Essa produção tem necessidade não só de uma massa de trabalhadores que trabalham e cooperam mas também supõe uma população ou superpopulação excedente.

O grau de integração dessa superpopulação no processo produtivo dependerá da criação do capital adicional que propiciará o nível da reprodução ampliada num momento determinado da produção. Desse modo, sua criação pode implicar uma necessidade de população crescente suscetível de ser colocada no mercado de trabalho de acordo com a criação do capital adicional.

Se por um lado existe uma parte da população que produz efetiva e diretamente o espaço através de determinado tipo de trabalho (agrícola, industrial), por outro lado existe uma parcela da população que participa indiretamente na medida em que seu trabalho não produz diretamente o espaço (comércio, serviços) mas viabiliza os primeiros. $\mathrm{E}$ temos ainda uma parcela da população que se encontra fora do mercado de trabalho ou porcue não participa definitivamente do processo social de produção ou porque foi expulsa do mercado de trabalho ou, ainda, porque faz parte do chamado exército industrial de reserva.

Todas as parcelas da população acabam - de uma maneira ou outra, desigual e diferentemente - apropriando-se de uma parcela desse espaço produzido socialmente. Isso ocorre na medida em que todos os indivíduos de uma maneira ou de outra habitam esse espaço, nele se movimentam, utilizam-se dos equipamentos coletivos sociais, consomem um espaço de lazer, etc.

O processo de apropriação do espaço serí, portanto, estabelecido pelo lugar que o indivíduo terá na classe social e, conseqüentemente, pelo lugar que esta ocupa na sociedade.

\section{II}

Nossos reflexões sobre o tema nos levaram a pensar no processo de produção do espaço sob dois pontos de vista: o do processo geral ligado à totalidade, o que nos leva à discussão do espaço global, o do processo específico, ligado às parcelas que compõem essa totalidade, o que nos leva à discussão da análise regional. Isso implica necessariamente em se considerar o processo de regionalização.

Esse processo apresenta-se como o movimeirto de criação e transformação da região. Essa afirmação nos leva a refletir sobre a noção de região, dentro da perspectiva teórica esboçada até aqui. A região apareceria como uma parcela da totaliclade do espaço geográfico e, nesse sentido, não poile explicar-se em si mesma, mas em sua relação dialética com a totalidade à qual pertence, isto é, com o espaço geográfico global (nacional ou mesmo internacional). É necessário levar-se em conta na análise que, se uma região se articula, se define e se determina em função da divisão interna do trabatho dentro de um espaço nacional, este, por sua vez se define pela divisão internacional do trabalho, ligado a outras nações do globo. A totali- 
dade considerada como pano de fundo da análise regional é o espaço produzido pela formação sconômica social capitalista, que ultrapassa o territótio de uma nação para abranger o espaço dos países capitalistas.

Nesse sentido é que a região, se bem que analisada separadamente do todo a que pertence, é parte indissociável dessa totalidade. A análise da parcela isolada do todo representaria assim uma abstração vazia desprovida de significância

A articulação da região com o espaço nacional ao qual pertence e deste com o internacional é determinada pela divisão do trabalho: local, regional, nacional e internacional.

Essa divisão se dá em dois níveis: na sociedade e no espaço e tanto um quanto outro têm como objetivo viabilizar o processo de reprodução ampliada do capital.

A divisão do trabalho é o elemento fundamental na determinação de regiões e do papel de cada uma dentro da totalidade do espaço.

Mas o que isto representa?

Aqui podemos fazer uma analogia entre indivíduo - classe social e região - totalidade do espaço geográfico.

Os homens que trabalham reunidos de modo complementar e que pelo seu trabalho se colocam de modo diferente frente ao processo produtivo, têm sua diferenciação dada pelo lugar que ocupam no sistema de produção. Esse sistema de prođução é determinado pelas relações em que os homens se encontram frente aos meios de produção, pelo papel que desempenham na divisão do trabalho, e, por conseguinte, pelo modo e a proporção em que recebem parte da riqueza de que dispõem.

O mesmo ocorre com o papel, a articulação e conseqüente importância de cada região dentro do processo de produção do espaço global. A divisão do trabalho que se estabelece no seio do processo produtivo entre os homens ocorre entre parcelas do espaço articuladas e determinadas pelo mesmo processo de produção. Desta feita, a região dentro do espaço global desempenha um papel complementar que a coloca de modo diferente dentro do processo produtivo e que implica necessariamente uma hierarquização espacial. Cada região terá seu papel determinado pelo lugar que ela ocupa no sistema de produção geral. Isso determina seu lugar na divisão espacial do trabalho $\mathrm{e}$, por conseguinte, o modo e a proporção em que recebe parte da riqueza social de que se dispóe. Assim se configura seu papel no processo de acumulação do capital

Do mesmo modo que a classe social não se distingue pela cor ou raça, isto é, por um elemento natural, a região não se diferencia nem se particulariza pela natureza, isto é, pela fertilidade do solo, pelos recursos naturais aí existente. A regionalização se define pelo precesso de trabalho. $\dot{E}$ ele que the dá o caráter social e não natural, do mesmo modo que ele dá o caráter social ao processo de produção. Isso quer dizer que está sempre presente na análise a divisão do trabalho em seus vários níveis: local, regional, nacional e internacional.

Assim como a distribuição de indivíduos na sociedade, a formação das regiões também é um processo desigual. E aqui se deve fazer uma ressalva que o desenvolvimento desigual das regiōes não é um fenômeno puramente econômico. Apesar de ter seu pressuposto primeiro no modo de produção da sociedade, sua determinação maior vincula-se à formação econômico-social.

A história do capitalismo, enquanto sistema mundial, é a história da internacionalização do capital, ou seja, da criação de um espaço econômico internacional, no qual o capital, em suas diversas formas (capital-dinheiro, capital-produtivo, capital-mercadoria) pode circular livremente. A origem 
do modo de produção capitalista consistiu precisamente na criação de um espaço econômico desta espécie dentro de diversos estados nacionais. Ao se acumular, o capital tende sempre a ampliar o espaço no qual se move, o que leva de um lado à expansão das fronteiras nacionais dos estados capitalistas e do outro à acumulação dessas fronteiras enquanto obstáculos de seu movimento. Pode-se interpretar a história dos últimos dois séculos como um permanente oscilar entre essas duas formas de expansão: a primeira, levando à expansão colonial do fim do século passado e às duas guerras mundiais, ao passo que a segunda acarretou o surgimento das Empresas Multinacionais e dos trustes internacionais. (Singer, 1976, p. 4).

Temos agora um espaço internacional mais amplo e mais integrado do que nunca na história do capitalismo, dominado por algumas centenas de Empresas Multinacionais. Sendo as Empresas Mu1tinacionais capital monopolista, este espaço é segmentado em termos de controle e planejamento centralizado de vários recursos produtivos, postos a serviço da maximização de lucros.

O Estado desenvolvimentista, que favorece a acumulação nacional de capital, desde que não se oponha à entrada de capital estrangeiro, também favorece a acumulação internacional da Empresa Multinacional. E essa acumulação é setnpre centralizada. O desenvolvimento do capitalismo está profundamente marcado pelo processo de concentração, tanto no perfil que assume como nos resultados econômicos e sociais. Trata-se, tanto, de um processo desigual de desenvolvimento, e esta noção envolve além de uma questão econômica, tamıbém seus aspectos, sociais, políticos e espaciais.

Galeano escreve que há dois lados na divjsão internacional do trabalho: um, que engioba alguns países que se especializaram em ganhar, e outro que engloba os que se especializaram em perder. $O$ desenvolvimento desenvolve a desigualdade. A força do conjunto do sistema imperialista descansa na necèssária desigualdade das partes que o formam e esta desigualdade assume magnitudes cada vez mais dramáticas. (Galeano, 1979, p. 3).

Do ponto de vista do espaço nacional, o processo de regionalização baseado na divisão espacial do trabalho assume as mesmas características da divisão internacional do trabalho, guardando as devidas especificidades históricas. Aprofunda-se e desenvolve-se a divisão do trabalho entre is espaços em função do processo de reprodução do capital. Cada vez mais se torna necessária uma subdivisão intrincada de operações entre as diversas etapas do movimento do processo produtivo, conseqüentemente do espaço, ao mesmo tempo em yute leva à subordinação do trabalho e de parcelas do espaço. O capitalismo continua a se descnvolver com tendência à concentração e, com ela, o grau de monopólio em suas variadas formas. O próprio crescimento do capitalismo de Estado serviu para reforçar essas tendências da concentração, de centralização e do monopólio.

Essa concentração do processo do capital se articula e se centraliza espacialmente nas cidades, as quais constituem o arcabouço político, econômico e social do país. A metrópole representa a esfera superior. E a partir dela que se completa o ciclo da produção, da circulação e da distribuição do capital. O processo de acumulação do capital ocorre concomitantemente ao processo de urbanização - como causa e efeito deste.

Se por um lado, como afirma Lojkine, o processo de urbanização capitalista atual aparece como a forma mais desenvolvida da divisão do trabalho material e intelectual, ele representa também formas da divisão social e espacial do trabalho. Indica uma contradição entre as parcelas diferenciadas do espaço na medida em que o processo de reprodução do capital se realiza centradamente.

O desenvolvimento capitalista acarreta, no Brasil, como nos demais países, uma concentração do 
capital na metropole nacional, que tende a reforçar a concentração espacial do processo de acumulação e concentração de renda. Na medida em que as maiores empresas capitalistas do país estão sediadas em São Paulo e tendem a crescer mais do que as restantes elas trazem maior soma de recursos para acumular em São Paulo.

O fato de São Paulo situar-se como centro hegemônico do processo de acumulação no Brasil acarreta uma pauperização relativa de outras regiōes do país. Ao lado da transferência direta de recursos para investimentos, uma outra fonte de concentração é proporcionada pela própria posição privilegiada da economia paulista na divisão regional e nacional do trabalho.

Se por um lado existe um processo de acumulação de recursos e investimentos, do outro ocorre processo de concentração populacional. O primeiro se faz através de transferência do capital e o segundo pela migração. $O$ processo de acumulação implicam um movimento da população para os centros que a sediam. "Se se admite que a migração interna é um processo social, deve-se supor que ele tenha causas estruturais que impelem determinados grupos a se pôr em movimento. Estas causas são quase sempre de fundo econômico - deslocamento de atividades no espaço, crescimento diferencial da atívidade em lugares distintos, e assim por diante e atingem os grupos que compõem a estrutura social do lugar de origem de um modo diferenciado. (...) Neste exemplo, a primeira onda de emigrantes é constituída por desempregados, a segunda por camponeses proletarizados." (Singer, 1975, p. 51).

A expansão do capitalismo no Brasil tem seu foco de acumulação espacialmente localizada no Sudeste, onde São Paulo, dentro dessa região, assume o papel de comando na produção do espaço brasileiro. A realização deste processo implica um movimento dialético de criação e destruição, que ocorre dentro do processo produtivo global, tanto no que se refere à população quanto no que se rè- fere ao espaço. Desse modo, começa a se articular uma produção espacial comandada por São Paulo que, por seu papel hegemônico, comanda, estrutura e articula outras regióes dentro do território nacional. Assim sendo, a destruição das economias regionais nada mais é do que a forma de reprodução e desenvolvimento do sistema em escala nacional.

Assim se articula um processo de produção geral do espaço, que se realiza de uma maneira desigual, através do movimento diferencial do processo de acumulação. O espaço se produz e se reproduz submetendo "parcelas diferenciadas do espaço nacional" ao centro dinâmico (político, econômico, social e de gestão) através da submissão ao processo produtivo do capital. Esse subordina parcelas do espaço às leis da reprodução através do controle do desenvolvimento do processo industrial que ora expropria os excedentes do capital para o centro de comando da acumulação, ora impõe sua produção em detrimento da produção local e regional, ora penetra como capital e absolve o investimento. Esse processo implica a captação da extorsão da mais valia para o centro nervoso do sistema. Exemplificando, o sistema cria mecanismo que permitem ao capital e ao centro espacial de acumulação principal de explorar a força de trabalho sem se deslocar.

\section{Considerações Finais}

$\mathrm{O}$ que pretendemos neste breve artigo, muito mais do que apontar soluções, é levantar algumas questões para o debate e reflexões sobre a estruturação do espaço geográfico do ponto de vista da população.

$\mathrm{O}$ que se questiona fundamentalmente é a abordagem quantitativa e abstrata que a população tem sofrido por parte dos trabalhos geográficos de um lado, e de outro a tentativa de solução desse problema simplesmente com a busca nos escritos de Marx. Mais do que isso, é necessário pensar a po- 
pulação enquanto agente da produção e da apropriação do espaço, enquanto produto do trabalho da sociedade global.

É necessário pensar a população não enquant’o soma de indivíduos, mas enquanto sociedade de classes. Uma sociedade ativa que, por meio do trabalho social, produz e reproduz sua existência, o mundo e o próprio espaço geográfico.

Logo, essa relação deve ser buscada no pro. cesso de trabalho da sociedade, na sua capacidade de criar os objetos de sua necessidade. Assim estaremos tratando de agentes ativos transformadores que imprimem e determinam a dinâmica da sociedade e do espaço, enquanto produtos da história. "O que os homens procuram na história são as transformações do sujeito da ação no relacionamento dialético homem-mundo, são as transformações da sociedade humana" (Goldman, 1970, p. 23).
O processo histórico é um fazer-se intenso, a partir da relação que se estabelece entre o homem e a natureza; ele está calcado, por outro lado, no desenvolvimento do processo de hominização, onde o próprio homem aparece como um produto da história.

Não se pode, portanto, dizer que o espaço geográfico sempre existiu ou que existe independente da sociedade que o produz. Ao mesmo tempo a sociedade apresentará, em momentos históricos determinados, especificidades definidas.

Faz-se, pois, necessário partir da reflexão da relação sujeito-objeto, na geografia; como essa relação evolui no pensamento geográfico e como ela se realiza e se justifica no momento histórico atual.

A partir dessa reflexão, o papel da população nos estudos geográficos poderá ganhar uma perspectiva mais concreta e real.

\section{BIBLIOGRAFIA}

1 - BEAUJEU-GARNIER, J.B. (1980) - Geografia da População, Editora Nacional, São Paulo, 2? Edição.

2 - CARLOS, A.F.A. (1979) - Reflexóes Sobre o Espaço Geográfico, Dissertação de Mestrado, USP, São Paulo, mimeografado.

3 - CARLOS, A.F.A. \& LENCIONI, S. (1981) A apropriação do Espaço capitalista, in Anais do 4․ Encontro de Geografia, A.G.B. - Rio de Janeiro.

4 - DoBB, M. (1978) - Economia Política e Capitalismo, Ed. Graal, Rio de Janeiro.

5 - Galeano, E. (1979) - As Veias Abertas da América Latina, Ed. Paz e Terra, Rio de Janeiro.

6 - GeOrge, P. (s.d.) - Ação do Homem, Ed. Difusão Européia do Livro, São Paulo.

7 - GEORGE, P. (1971) - Geografia da População, Ed. Difusão Européia do Livro, São Paulo.

8 - GOLDMAN, L. (1970) - Ciências Humanas $e$ Filosofia, Ed. Difusão Européia do Livro, São Paulo.
9 - LENIN, V. (1966) - Obras Escogidas Vol. 3, 2. Edição, Editora Progresso, Moscou.

10 - LOJKINE, J. (1979) - O papel do Estado na Urbanização, in Forti, R. - Marxismo e Urbanismo Capitalista - textos críticos, Ed. Ciências Humanas, São Paulo.

11 - MARX, K. (1968) - Fondementes de la critique de l'economie politique, ébouche 1857-1858 Editions Anthropus, Paris, V. II e III.

12 - MARX, K. \& ENGELS, F. (1974) - Ideologia Alemã, Editorial Presença, Lisboa, Vol. I.

13 - SANTOS, Milton (1979) - Espaço e Sociedade, Editora Vozes, Petrópolis.

14 - SINGER, Paul (1976) - Divisão Internacional do Trabalho e Empresas Multinacionais - CEBRAP, São Paulo - mimeografado.

15 - SINGER, Paul (1975) - Economia Política da Urbanização, Ed. Brasiliense, CEBRAP, São Paulo. 